\title{
LA SINFONÍA DE LETRAS DANZA EN LA IMAGINACIÓN HASTA DAR CUERPO A LAS PALABRAS.
}

\section{The symphony of letters dance in the imagination until they give body to the} words.

\section{Robinson Salazar-Pérez}

https://orcid.org/0000-0003-0787-6876

Como citar: Salazar-Pérez, Robinson. (2020). La sinfonía de letras danza en la imaginación hasta dar cuerpo a las palabras. Telos: revista de Estudios Interdisciplinarios en Ciencias Sociales, 23 (1), Venezuela. (Pp.3-7).

DOI: www.doi.org/10.36390/telos231.01

Las palabras esbozan o denotan una imagen, cosa u objeto, sin embargo, al momento de encadenarlas en oraciones complejas, armonizadas en párrafos y argumentaciones bajo la conducción de un pensamiento educado y disciplinado, da fruto a escritos diseñados bajo la lente reflexiva de un escritor empeñado en escudriñar, describir, desentrañar y explicar un fragmento de la realidad que lo circunscribe.

Bajo el paraguas de la reflexión desafiante y la responsabilidad de dar cuenta sobre los acontecimientos apresurados e inéditos arrojados por la Nueva Normalidad, Telos: Revista de Estudios Interdisciplinarios en Ciencias Sociales convocó a estudiosos de las Ciencias Sociales a encarar con inteligencia y acuciosidad los recientes fenómenos apremiantes y requeridos de ser explicados bajo un análisis caviloso y concentrado en cada aspecto y especialidad de los autores que nos prestaron su pluma perspicua con el objetivo de dar cuenta sobre qué está aconteciendo en nuestra realidad social.

Con celeridad y despliegue juicioso de habilidades teóricas, desde Angola presentamos un texto tejido bajo la égida de las concepciones teóricas y necesidad incorporar las Estrategia de Ciencia, Tecnología e Innovación en el área educativa con el firme objetivo de promover el ejercicio hacia una apropiación de la CT\&l a fin de insertar a los estudiantes a la demanda de la sociedad en plena transformación digital.

Otra aportación la reseñamos en ese camino de transformación acelerada donde muchos segmentos de la sociedad quedan ocultos, otros marginados y negados de su participación crucial y necesaria para dar armado a una comunidad dialógica,

\footnotetext{
*Universidad Autónoma de Sinaloa/México. Director de www.insumisos.com. Correo electrónico: salazar.robinson@gmail.com
} 
inclusiva, democrática y donde quepamos todos. Es la ruptura del colonialismo inoculado en nuestros pensamientos, donde los puntos de vista diferentes que el otro pueda tener no pasen desapercibidos ni ignorados por el yo. Es momento de transitar a la transmodernidad, en pensamiento de Enrique Dussel, con el propósito reconocer y aceptar la diferencia, la diversidad negación del pensamiento único.

La inserción de un artículo sobre lo realizado al interior de amplio espectro de la sociedad en re-construcción, cuya evidencia son los embates de diversos factores que están instigando eventos y dinámicas inexploradas, induce a la inquietud por llevar a cabo nuevas pesquisas para entender y facilitar la inserción de grandes segmentos sociales al mundo de la enseñanza y economía digital, la experimentación con estudiantes de postgrado en el uso y aplicación de técnicas de learning analytics basado en el modelo de Chatti y aplicación de algoritmo para conocer las conductas, aspiraciones y deseos de los alumnos, a su vez el uso del tiempo, actividades esenciales u toma de decisiones sobre su quehacer.

Nos alienta el texto esbozado con despliegue analítico y abordado con fundamentos teóricos Robert Alan Dahl aplicados al mapa de la democracia en algunos países de América Latina. Realza el dibujo asimétrico en la instrumentación de políticas públicas, respeto a los Derechos Humanos y en otros casos vulneración de las garantías Constitucionales por el sesgo autoritario de sus gobiernos. Deja entrever la disparidad entre naciones con un reglamentarismo jurídico consolidado y republicano y aquellos inclinados a la imposición unipersonal del poder bajo la férula del liderazgo compulsivo.

En otro orden de ejercicio escrito, apreciamos la aportación reflexiva extraída de la realidad de hoy, y atañe a los jóvenes desafiantes de la Nueva Normalidad y los empañamientos de la pandemia. El eje del trabajo fundamenta condiciones de incertidumbre y adversidad extraordinarias para desarrollar una actividad emprendedora; los obstáculos a sortear aplicando dinámicas particulares exigidas por un contexto infortunado arrojaron resultados sugerentes en la juventud, entre ellos resiliencia, detección de oportunidades y visión positiva del futuro las cuales incidieron en su decisión de emprender un negocio en medio de la propagación del Covid 19.

Contamos con un texto invitándonos a conocer los estudios y procesos de innovación abierta en las pequeñas y medianas empresas, de la industria automotriz de México, sector económico vital para el país y su inserción en el TMEC, llevándolo a ocupar el 4 lugar de nación exportadora de autos. Cabe señalar la significancia de la manufactura automotriz la misma incluye: fabricación de automóviles y camiones, asimismo producción de partes para vehículos automotores, rubro coadyuvante con el $3.8 \%$ del Producto Interno Bruto (PIB) nacional y genera alrededor de un millón de empleos directos. Este aspecto relevante ocupó la pluma de los autores para aplicar 300 encuestas en explorar, bajo un modelo de ecuaciones estructurales, el valor 
intrínseco de la innovación abierta y sus efectos positivos en el rendimiento empresarial y crecimiento de la región del bajío y el país.

Ahora bien, la actividad empresarial no sólo está concentrada en producir, comercializar y obtener ganancias; existen funciones específicas de relevancia social entre ellas el área de la Responsabilidad Social, fundada en un proyecto de construcción colectiva orientada a generar un Impacto social y de beneficio común de sustentabilidad para la población y la naturaleza. El trabajo prestado por dos féminas involucradas en la investigación de la administración comprometida y acuciosas, orienta de manera persistente los derroteros de una gestión empeñada en equilibrar la actividad económica con la sociedad, empoderamiento de nuevos liderazgos y articulación de saberes y competencias en un denso entramado de responsabilidad compartida, realzando los valores humanos, sumando voluntades que conlleven a la denominada gerencia emancipadora, cuyo eje explicativo embona con las demandas sociales y el cuidado urgente del planeta habitado por todos nosotros.

En un apartado concertado para abordar un tema específico que preocupa y ocupa el pensamiento de una gran cantidad de docentes e investigadores, la Nueva Normalidad, tuvo resonancia y atracción de 6 plumas activas de la escritura crítica y desafiante.

En primera instancia contamos con la apertura del debate con el tema del Sujeto Político ante el cuadro de diversidad y amplio mapa ideológico prevaleciente en la actualidad y las maneras posibles de articular acciones colectivas conducentes a transformar el entorno dominante e inequitativo. Obviamente, existen algunas rémoras inaplazables para remontar, las cuales son herencias del modelo neoliberal, entre ellas desmontar desaprendiendo/aprendiendo la negación del individualismo, la recuperación de la aldea, el lugar y articular fuerzas negando el pensamiento y conducción personal, compulsivo y negadora de la importancia y vitalidad del concurso de las comunidades en rebeldía.

Es obvia la tendencia modificadora dibujada en el horizonte del Nuevo Orden Mundial, la pandemia, los confinamientos obligatorios, el reacomodo de nuevas formas de trabajo y de relacionarnos conllevan a identificar reconfiguraciones globales en su mayoría mediados por los efectos del Covid19, vislumbran la edificación de un ordenamiento global con bases fortalecidas para seguir consolidando el capitalismo tecno-financiero, las tecnologías de la información y la comunicación apoderándose de las relaciones sociales, sustituyendo las basadas en la interacción intersubjetivas, subordinando y condicionando las conductas de consumo, imponiendo la educación virtual y creando las condiciones necesarias para la Nueva Normalidad. Es un texto bisagra y conector de la destrucción de las certezas y la incertidumbre de lo social con el advenimiento de una sociedad en el Siglo XXI.

Desde el cono sur nos llegó el trabajo pormenorizado sobre la violencia contra las mujeres, el lugar en dónde se produce, ligado a la explotación femenina del trabajo 
doméstico y la manera en que se ha intensificado en tiempos de la pandemia. La autora avanza en algunas claves del sexismo manifiesto por el confinamiento de la pandemia, para entender el significado que el trabajo reproductivo tiene en diferentes territorios sociales donde tiene lugar. Tomando como campo de observación los acontecimientos desarrollados en Argentina en tiempos de Covid19, concluye aseverando, la crisis causada por la calamidad de salud implanta una alteración en la agenda feminista para las próximas reivindicaciones, enfatizando en la politización y la dinámica posible de sus actividades insurrectas y de re-empoderamiento en los barrios, enlazadas con las demandas de la comunidad sin dejar de lado su papel en la vanguardia reclamante.

Para el ámbito escolar, los efectos del Covid-19, lo revelan e imponen como nueva enfermedad en contagio a nivel mundial, dando lugar a la instrumentación de modalidades virtuales para impartir aprendizajes sin menoscabo de introducir en el diálogo de la comunidad virtual el temor, los miedos e inseguridad prevaleciente en el entorno social, principalmente en los sectores donde impera la desigualdad social. No obstante, la ensayista indaga, re-piensa y propone la necesidad de recuperar la humanización de los agentes educadores, del sistema educativo y la sociedad en general para contribuir con la nueva modalidad de acercar los conocimientos a los educandos reconociendo la existencia de diferentes estratos sociales y diversidad cultural. Plantea crear formas y modelos de reproducción de empatía para posibilitar la educación inclusiva con todos aquellos que no cuenta con acceso a las herramientas tecnológicas y manejo de estas.

La pregunta de mayor consideración, la cual nos asalta la razón, fincada en lecturas acumuladas antes de la pandemia. Consiste en saber la magnitud de las alteraciones y cambios suscitados en las diversas esferas de la sociedad.

El texto sobre sistemas sanitarios y reproducción familiar da cuenta de los cambios ocurridos en las ciudades, los sistemas de salud y la familia extensa a partir de las afectaciones provocadas por el COVID-19. La dinámica relacional de los trabajadores de la salud solicitando el apoyo de la familia extensa, los factores de riesgo implícitos al otorgar el soporte afectivo o de otra índole y finalmente el impacto de ese sustento en el incremento del trabajo, perturbaciones en su vida cotidiana.

Y finalmente, cerramos el número 23-1 que corresponde a enero/abril 2021 con la reflexión escrita sobre el confinamiento ocasionado por la pandemia Covid-19 desde marzo de 2020, sin dudas aceleró la innovación tecnológica, adelantó el uso de dispositivos en diversas áreas de la actividad humana y orientó a los gobiernos, empresas, clubes, organizaciones sociales entre otras áreas de convivencia humana, a definir medidas para atender la emergencia sanitaria sin desestimar sus operaciones durante el aislamiento.

Las modificaciones organizativas de trascendencia hasta ahora observables son el teletrabajo o trabajo en casa, resaltando las bondades y uso de autonomía en el trabajador, flexibilidad de horarios para obtener un mayor equilibrio entre la vida laboral 
y la vida familiar. Sin embargo, en el marco de un capitalismo de vigilancia han puesto en marcha mecanismos de control digital, vigilancia y monitoreo de las actividades de los trabajadores, lo cual niega la autonomía adquirida y manejo adecuado de los horarios laborales.

No es un dato menor la participación de mujeres académicas en el número puesto ante sus escrutadores ojos, quienes superaron a los docentes varones cooperando de manera oficiosa y certera con sus textos analíticos. Enhorabuena por todas ellas y sus quehaceres académicos, dejando las puertas abiertas para próximas aportaciones.

Gracias por la oportunidad brindada para participar como coeditor del primer número del año 2021. 